\title{
Constructivism and the Logic of Political Representation
}

\section{THOMAS FOSSEN Leiden University}

\begin{abstract}
7 here are at least two politically salient senses of "representation"-acting-for-others and portraying-something-as-something. The difference is not just semantic but also logical: relations of representative agency are dyadic (x represents $\mathrm{y}$ ), while portrayals are triadic (x represents $\mathrm{y}$ as $\mathrm{z}) . \mathrm{I}$ exploit this insight to disambiguate constructivism and to improve our theoretical vocabulary for analyzing political representation. I amend Saward's claims-based approach on three points, introducing the "characterization" to correctly identify the elements of representational claims; explaining the "referent" in pragmatic, not metaphysical terms; and differentiating multiple forms of representational activity. This enables me to clarify how the represented can be both prior to representation and constituted by it, and to recover Pitkin's idea that representatives ought to be "responsive" to the represented. These points are pertinent to debates about the role of representatives, the nature of representative democracy, and the dynamics of revolutionary movements.
\end{abstract}

D ifferent forms of political activity go by the name of "representation." An MP may claim to genuinely act on behalf of his constituents, while his opponents represent him in the media as being in the pocket of big money. A government that purports to represent the will of the people also represents that people as a unity. A resistance movement might claim to represent the interests of the downtrodden, while representing the regime as a kleptocratic elite. There are at least two politically salient senses of the word "representation" involved here: the sense in which someone acts for someone in the capacity of a representative, as the elected may be said to represent their voters, and the sense in which a picture represents what it is a picture of. Call the former acting-for-others (or representative agency) and the latter portrayingsomething-as-something (or representation-as). ${ }^{1}$

The key point to recognize, I will argue, is that the difference between these two senses is not merely semantic, but also logical. When a representative acts on behalf of a constituency, the relation is dyadic: $x$ represents $y$. In contrast, portrayals of something

Thomas Fossen (D), Assistant Professor of Political Philosophy, Institute of Philosophy, Leiden University, P.O. Box 95152300 RA Leiden, t.fossen@phil.leidenuniv.nl.

For feedback, discussion, and inspiration for this paper, thanks to Dario Castiglione, Frank Chouraqui, Victor Gijsbers, Tim Heysse, Frederike Kaldewaij, Hans Lindahl, Mihaela Mihai, Laura Montanaro, Alessandro Mulieri, Sofia Näsström, Johan Olsthoorn, Andrew Schaap, Mathias Thaler, an audience at the University of Exeter, and several anonymous referees.

Received: March 14, 2018; revised: February 22, 2019; accepted: March 23, 2019; First published online: May 14, 2019.

\footnotetext{
${ }^{1}$ Other languages than English have multiple words that translate various uses of "to represent." German, for example, has among others vertreten (acting-for) and darstellen (to portray or render). Pitkin's terminology of "acting for" and "standing for" was meant to distinguish these, but is unfortunate as it fails to capture the triadic structure of representation-as, which she did notice (1967, 69-72). On the various meanings of representation, see Mulieri (2016) and Sintomer (2013).
}

(or someone) as something exhibit a triadic relation of representation: $x$ represents $y$ as $z$. The distinctive logical form of representing-as, in contrast to representing (simpliciter), remains overlooked by theorists of political representation. Ambiguity and confusion result. My aim is to explicate this basic insight, and to demonstrate its significance for scholarly debates about representation in politics-including those concerning the nature of representative democracy, the tasks of representatives (in electoral and non-electoral contexts), and the claims of revolutionary movements.

I proceed through an engagement with the "constructivist turn" in the literature on political representation (Disch 2015) - a wave of recent work that foregrounds esthetic, performative, and creative aspects of representation. Constructivists maintain that the identity, interests, or preferences of the represented are not given prior to representation but shaped through being represented. Constructivism about representation is not new (Alcoff 1991; Ankersmit 1996; Bourdieu 1991; Lefort 1988). It has a lineage in poststructuralism and figures prominently in feminist theory, cultural studies, and esthetics (Disch 2016; Goodman 1968; Hall 1997). In political theory, the idea goes back at least as far as Thomas Hobbes's claim that a people only exists in being represented by the sovereign (2012).

Today, constructivists aim to rethink three fundamental issues: what representation is; how it should be done; and what it has to do with democracy. First, representation refers not just to the relation between representative and constituency, but more fundamentally to the ways in which such relations come about, conceived in terms of the performative role of agents making "representative claims" (de Wilde 2013; Saward 2010), or of complex systemic processes that constitute representative government (Disch 2011; Urbinati 2006). For example, women's representation is not just about who gets to speak for women, but also how gender differences and women's interests are constituted and rendered politically salient (Celis et al. 2014; Squires 2008). Thus conceived, political representation is not essentially tied to elections with predefined territorial constituencies 
but occurs in a wide range of settings and by various kinds of agents - potentially including activists, lobbyists, and bureaucrats (Kröger and Friedrich 2013; Lord and Pollak 2013). Indeed, some theorists see a link between representation and revolution, because representation is at work in any appeal to a collective "we." Thus, they interpret participatory movements like Occupy not just as denying that they are represented by the system, but as themselves engaged in counterrepresentation (Brito Vieira 2015; Geenens et al. 2015).

Second, this rethinking of representation prompts reflection on its normative evaluation: what makes for a good representative? And what can render representation legitimate? If politicians shape the preferences of their voters, those preferences cannot provide an independent benchmark for evaluating the representatives' actions (Disch 2011). And if nonelected representatives call forth their own constituency, then they are not constrained by the prior authorization or post hoc accountability which electoral procedures are supposed to provide. In short, the quality of representation cannot be understood in terms of correspondence between representatives' decisions and an antecedent will of the represented. Therefore, constructivists look elsewhere for normative criteria, for instance to the spirit in which representation is performed (Näsström 2015; Saward 2010), whether it manages to empower its constituency (Montanaro 2012), or the systemic qualities of the larger process in which it occurs (Disch 2011; Kuyper 2016).

Third, constructivists reexamine the relation between representation and democracy, asking to what extent representing is a democratic practice, and conversely, whether democracy is inherently representative. Many regard the opposition between "direct" and "representative" democracy as misconceived, because no democratic politics-even radically participatory models - can do without forms of representation, for one thing because it must invoke the name of "the people," who are never fully present (e.g., Näsström 2006; Urbinati 2006). This is not necessarily to endorse actually existing electoral democracies, but to ask which forms of representation are conducive to selfgovernment.

Getting a grip on the various senses of representation is crucial for interpreting and evaluating these ideas (Pitkin 1967, 227-8). But unfortunately, much of the literature remains vague on precisely this point (Rehfeld 2017, 55-7). Although constructivists emphasize that political representation has an esthetic dimension, I will show that they fail to consistently distinguish between acting-for-others and portrayingsomething-as-something. As a consequence, the basic idea of constructivism remains highly ambiguous. Only by recognizing the distinctive form of representation-as can we make sense of the thought that representation constitutes the represented. Since in representation-as there are two distinct senses of "what is represented," it turns out that the represented can be in some sense prior to being represented (qua referent), and constructed through representation (as characterized in the object). Recognizing this point is key to fleshing out the implications of constructivism for debates about the role of representatives, the nature of representative democracy, the claims of revolutionary movements, and so on. This article does not develop those implications in detail, but it does offer a sharpened conceptual toolkit for studying political representation and a better grasp of the basic idea of constructivism.

I start off with a conceptual analysis of Michael Saward's influential theory of the "representative claim" (2010). Recognizing the triadic logic of portrayal affords three important improvements to Saward's analytical framework. First, I show that his analysis cannot account for representations-as. To remedy this, I introduce a new term, the "characterization." That move helps to clear up a puzzling and controversial further issue: how to understand the notion of the "referent"? Critics have argued that this notion commits Saward to a dualism between representation and reality that is hard to square with his constructivism (Decreus 2013; Disch 2012b; Thompson 2012). I side with Saward in arguing that we cannot do without the notion of the referent, but I offer a pragmatic interpretation of it that sidesteps this metaphysical dispute. The third improvement is to distinguish explicitly between several types of political performance: acting in the capacity of a representative (or constituent); portraying someone as a representative (or constituent); and portraying someone substantively, for example, as having such-and-such interests. To speak of "the representative claim" (singular) is misleading: there are multiple representational activities in politics. These conceptual clarifications are pertinent to any claimsbased normative or empirical study of political representation, as the failure to adequately conceptualize and identify the elements of such claims will compromise the results.

Finally, to disambiguate the thought that representation is constitutive of the represented, I revisit Hanna Pitkin's idea (1967), rejected by constructivists, that the represented are logically and normatively prior to being represented. Recognizing the distinctive form of representation-as enables us to see that constructivism is not just compatible with this idea, but depends upon it. This will help to make sense both of the idea that representation could shape the identities or interests of existing groups, and also the more radical notion that representation could bring about the existence of groups and hence partakes of constituent power. To illustrate the normative significance of this analysis, I offer an explanation of Pitkin's claim that representatives ought to be responsive to the represented and argue that the constructivist critique of that idea, developed most carefully by Lisa Disch (2011, 2012a, 2012c), misses the mark. On this interpretation, responsiveness turns out to be compatible with constructivism after all. The point here is not to settle disputes about the normative implications of constructivism, still less to suggest that they can be resolved just by means of conceptual analysis. Rather, the point is that the failure to recognize different senses of representation hampers our ability to develop those implications. 


\section{UNPACKING THE REPRESENTATIVE CLAIM}

A second complication that besets debates about political representation, besides semantic ambiguity, is that the phenomenon (or phenomena) can be conceptualized from different directions. To appreciate Saward's contribution, it helps to start by distinguishing two of these, if only schematically. One approach starts with the assumption that there is a phenomenon in the world that the concept is supposed to refer to, and tries to articulate the necessary and sufficient conditions for something to be that, rather than something else. One can then use that account to explain how the concept is used appropriately in a particular context. Andrew Rehfeld's work is paradigmatic of this angle of approach:

A concept of 'representative' should help us explain the circumstances under which, for example, it is correct to say that Edward Kennedy was the representative of Massachusetts in 1984 but my mother Beverly was not. And a concept of 'representative' would also help us explain how the term is deployed in a range of formal and informal settings [...]. What we are suggesting is a concept that explains the features that all individuals who are labeled 'representative' (noun) share [...] (Rehfeld 2017, 60).

Call this a semantics-first approach, because it aims to fix the content of the concept-what it means, understood here in terms of its correspondence to certain given objects - and deploys that as a standard for the correctness of claims in which the concept is used.

A less familiar strategy for conceptualization inverts this direction of enquiry, trying to account for the meaning of a concept on the basis of its practical use. This pragmatics-first approach starts from the observation that people deploy the concept in question in certain practical contexts (e.g., making conflicting claims about who represents whom) and tries to understand what they are doing in using it. If one assumes that the meaning of a concept can be understood in terms of its use (as pragmatists and poststructuralists typically think), then it makes sense to try to derive a definition of a concept (what it means) from an account of the role the concept plays in certain social practices (Fossen 2019, 297-9). Thus, one could try to conceptualize political representation by starting, not with what it means for someone to $b e$ a representative, but what one does in claiming that someone represents someone. In this way, one avoids having to make prior assumptions about the essential features of the phenomenon in question.

Saward favors a pragmatics-first approach, although he does not put it in these terms. He considers the pragmatics of claims to "represent"-aspects of their use-as key to understanding the phenomenon: "representation exists primarily by virtue of its being done-practiced, performed, claimed" (2014, 725; cf. 2017). As he puts it, representation must be conceived as "event," not "presence," and "it is the rendering of such a claim of presence that is most crucial to understanding political representation" (Saward 2010, 39). ${ }^{2}$

So what is it, on Saward's account, to make a "representative claim"? He states that a representative claim is "a claim to represent or to know what represents the interests of someone or something" (or their values, preferences, etc.) $(2010,38)$. To unpack what this involves, Saward proposes an analytical framework with five elements: "A maker of representations puts forward a subject which stands for an object that is related to a referent and is offered to an audience" $(2010,36)$. For example, a party for the elderly presents itself as a subject, acting for an object, "the elderly," conceived as a constituency with distinct interests. The party itself, or someone making a statement on their behalf, would be the maker of the claim; and the audience could be voters, or viewers. The object must not be confused with the referent, which is elderly people as such, irrespective of the way in which they are represented. Representation, so conceived, is not a oneoff event but a back-and-forth: "an ongoing process of making and receiving, accepting and rejecting claims [...]" (2010, 36). A relation of representation is never a fait accompli, but at best a fragile achievement that remains subject to potential contestation.

Among the attractions of Saward's proposal is that he distinguishes between the maker of a claim and its subject. A representative claim may be made on behalf of someone else, as when a pundit claims that a party articulates the views of the elderly well. A second strength is that it highlights the role of the audience. If no one votes for the party for the elderly, they fail to represent-not merely because they fail to win seats, but because old people apparently have not come to see themselves as they were portrayed by the party. The audience's response to the claim is key to whether representation comes about. Finally, the framework is flexible, enabling us to analyze claims in a variety of contexts, not just elections; for instance, in an oft-cited example, Saward uses it to explicate Bono's claim to represent poor people in Africa $(2010,82)$.

But three points require clarification. First, the analysis invokes rather than explains the notion of representation, most obviously in the relation between subject and object ("stands for"). Second, the definition of the representative claim is ambiguous: claiming to "represent the interests of someone" might mean purporting to act on behalf of that person, or portraying their interests in a particular way. Saward makes explicit that he means both: it is to claim the "status" of a representative, but also to make "descriptive and substantive claims" about the represented $(2010,46)$. Yet, what the interests of the elderly are and who is supposed to act on their behalf are different questions. Saward applies his analytical framework indiscriminately to both types of claim. I show below that this does not work. The third issue concerns the notion of the

\footnotetext{
${ }^{2}$ Saward also suggests that he aims to explain "what representation does, rather than what it is" (my emphasis) (2010, 4), but from a pragmatist viewpoint this is a false opposition.
} 
referent. Saward says that the referent is "related" to the object, but how exactly? He claims that the represented object is a contestable "idea" or "interpretation" of its referent; "a picture, a portrait, an image," not the "thing itself" $(2010,36,74,121)$. I discuss this below. For now, what these formulations indicate is that the relation between object and referent is again one of representation. Within the representative claim, we find a proliferation of representations.

This, in a way, is precisely Saward's point. He insists that all political representation involves some esthetic element: "At the heart of the act of representing is the depicting of a constituency as this or that, as requiring this or that, as having this or that set of interests" (2010, 71). Of course, depicting is representing, in the sense of portraying. This is Saward's core idea: that in order to be a representative (someone who acts for a constituency), you must be successfully portrayed as such; and this in turn involves portraying the represented in one way or another. So Saward invokes representation in the sense of portrayal to explain representation in the sense of acting-for-others. The question is whether his theoretical framework is adequate for the task. Let's examine this more closely.

\section{REPRESENTATION-AS}

This section explicates the basic idea that there is a logical difference between relations of representative agency and representation-as, and uses that insight to show that Saward's framework fails to capture something crucial about the latter. I proceed by way of an example, offering two statements about relations of representation that might occur in the same situation. When trying to apply Saward's framework to each statement, we will find that it cannot identify all the salient elements in the case of representation-as.

For purposes of exposition, I deploy an example from a juridical context: a trial. Familiar controversies abound as soon as we consider political examples. What is it for an MP to represent a constituency, an activist, the disadvantaged, or the government, its people? By using a legal analogy, I do not mean to suggest that political representation must necessarily take place in a formal setting, that the responsibilities of political representatives are the same as those of legal representatives, or that representative agency is always a one-on-one relationship between individuals. As we shall see later on, however, in political contexts the two forms of relation come apart in analogous ways.

Compare the following statements:

(a) The lawyer represents her client before the court.

(b) In her closing statement to the jury, the lawyer represents her client as an innocent bystander.

Each statement posits a relation of representation. But the relations differ in a number of respects. First, they differ as to their relata, the things they consider as standing in a relation of representation: (a) talks of a relation between two individuals, whereas (b) invokes a relation between a statement (made by an individual), an individual, and an account of a person's role in some incident. Second, they differ semantically, or with respect to the sense of the relation involved. "Representation" means different things in both cases: being someone's representative in (a) and portraying them in some way in (b). Third, they differ in the number of relata: The relation of subject and object in (a) is dyadic ( $x$ represents $y$ ), whereas in (b) it is triadic ( $x$ represents $y$ as $z$ ).

This last point is crucial to my argument. By calling this an aspect of the logical form of the relations, I mean to highlight that it is something about their structure at the most abstract level: whether it involves two or three relata. ${ }^{3}$ To say that relations of representation have such a structure is not to make a controversial metaphysical claim. Whether one thinks of such relations as existing prior to claims about them, or as brought into being by such claims, either way the relations (and claims about them) relate a certain number of terms. My point is just to make that explicit. So in describing these relations as dyadic and triadic, I do not mean to discard contextual factors as unimportant-I am just focusing, for the moment, on the structure of the relation of representation posited in the statement.

Despite the terminological overlap, this distinction of logical form should not be confused with the distinction between "dyadic" and "systemic" accounts of political representation proposed by Jane Mansbridge (2003). Mansbridge argues that political representation is poorly conceived when thought of exclusively in terms of a principal-agent relation between constituency and representative; instead, it should be understood and evaluated at a systemic level, where it emerges from complex and ongoing interactions among a plurality of agents (voters, parties, media, interest groups, and so on). Mansbridge's distinction is ontological in that it pertains to the kinds of things that might be said to be representative of something (individual agents versus a system as a whole), whereas my focus is on the logical form of the relations (two or three terms). When we speak of an entire system of governing institutions as representative of a heterogeneous people, there are logically speaking two terms to that relationship (although each of them is ontologically complex and perhaps dependent on the other).

With those caveats in mind, let us try to apply Saward's framework to each statement.

(a*) The lawyer (subject) represents her client (object) before the court (audience).

\footnotetext{
${ }^{3}$ Another example of a two-term relation is motherhood: a mother is always mother to some child. She might have multiple children, there could be another parent, but that is incidental to this person's being mother to this child. This holds irrespective of whether motherhood is understood in biological terms or as a socially constructed role. A good example of a three-term relation is a sale: there is no sale without buyer, seller, and something that is sold. The number of relata is just one logical aspect of the relation. Others include symmetry (does " $x$ represents $y$ " entail " $y$ represents $x$ "?) and transitivity (if " $x$ represents $y$ " and " $y$ represents $z$," does it follow that " $x$ represents $z$ ")?
} 
Here, the subject is also the maker, or perhaps participants in legal practice collectively are the makers. The referent in Saward's terms would be the client, not qua client but in other respects.

(b*) In her closing statement (subject), the lawyer (maker) represents her client (?) as an innocent bystander (?) to the jury (audience).

Note to begin that the subject-what does the representing, put forward by the maker-is different in kind: in (a), it is an agent, and in (b), a statement. This should not be surprising, since the former is tailored to invoke acting-for-others, and the latter portraying-as. In discursive representation, the subject (or signifier) is a claim or statement, just as with a portrait the subject is the painting, not the painter.

Complications arise when we consider the object, what is being represented. In (a), this seems clear enough: the client. But in (b), the object appears doubled. The lawyer's statement is about her client, but also in some sense about an innocent bystander; more specifically, it concerns her client as an innocent bystander. This does not fit Saward's categorization. Should we say that "her client" is the object [as in $\left.\left(\mathrm{a}^{*}\right)\right]$ ? But then we leave an element unaccounted for, because "an innocent bystander" is certainly not the referent. So, is "an innocent bystander" the object, and the client, the referent? But if the subject is supposed to represent ("stand for") the object, as Saward says, this overlooks something significant: The closing statement portrays not just any innocent bystander, but a very specific one. The remaining alternative is to say that "the client as an innocent bystander" is the object. And that is correct, I think, but we should not leave it at that, because it lumps together different elements.

Nelson Goodman observed an analogous ambiguity in saying what a picture is a picture of. Consider, for example, a painting of a fragile-looking elderly man. Suppose the label indicates that it is Churchill. So the picture represents Churchill (or so it is claimed). But it could also be said to represent a fragile old man. "Saying that a picture represents a so-and-so is thus highly ambiguous as between saying what the picture denotes and saying what kind of picture it is" (Goodman 1968, 22). Goodman disambiguates this by suggesting that when $x$ represents $y$ as $z, y$ signifies the referent, and $z$ signifies the kind of representation it is. Thus, the painting may be said to represent Churchill as a fragile old man, or, as Goodman would say, to be a fragile-oldman-picture of Churchill. The key point is that claiming that $x$ represents $y$ as $z$ is doing two things: to denote or pick out something (the referent) and to present it in some specific way-to characterize it somehow, or to "allege something" about it [as Pitkin put it (1967, 68-72)]. This applies to discursive and visual representations-of-something-as-something. In either case, what the referent is represented as is of course a matter of interpretation. Perhaps the painter meant to portray the statesman as pensive, rather than fragile. And what is denoted is also questionable. A viewer may see that the painting depicts an elderly person, but fail to recognize Churchill. Or perhaps she takes the painting to say something about the state of Britain as a whole, not just Churchill. Portrayals are contestable both as to what they denote and how they characterize it.

Following these clues, I submit that, in (b), "her client" is a name for, a way of mentioning, the referent. Strictly speaking, "an innocent bystander" is not what the representation is about, but how the referent is portrayed; call it the characterization. And the client qua innocent bystander is the object: the object denotes and characterizes the referent. So we get:

$\left(\mathrm{b}^{* *}\right)$ In her closing statement (subject), the lawyer (maker) represents [her client (referent) as an innocent bystander (characterization)][object] to the jury (audience).

To sum up, the relations of representation in actingfor-others and portraying-as are logically distinct, and Saward's framework must be amended to capture the latter by introducing the notion of the "characterization."

\section{IS ALL ACTING-FOR-OTHERS REPRESENTATION-AS?}

Before developing the implications of this abstract point, there is an important objection to consider. Is there really a distinction between dyadic and triadic relations of representation? One might think that the difference between (a) and (b) is merely apparent, that acting-for-others is also a form of representation-as, and that I've arbitrarily left the tertiary element (the characterization) out of the description. Just as a picture characterizes its referent in a distinctive way, so too a representative agent always represents in a particular way - namely by performing certain actions rather than others. The lawyer only represents (acts for) her client by doing certain things in order to defend him: showing up in the courtroom, making statements, issuing objections, and so on. So could the relation of representative agency in (a) not just as well be described as triadic?

Note that this objection, if convincing, strengthens the case for amending Saward's account, because it would imply that his analysis is insufficient even for paradigmatic relations of acting-for such as (a). But I do not think that it is a mistake to say that there is a distinctly dyadic sense of representation (simpliciter) in contrast to representation-as. The key question is this: what is the $z$ that remains unstated in my rendering of (a) and which is supposed to characterize the referent?

One suggestion would be that the lawyer represents her client as a client. But that does not capture the point of representative agency, because by the same token we could say that she represents herself as a lawyer. We could not, however, just as well say that she acts on her own behalf in the courtroom.

Alternatively, the idea behind the objection could be that the characterization lies in the performance, in the way in which the representative exercises her role. 
Should we say then that the lawyer characterizes the client as performing whatever she does on behalf of her client? But besides offering statements about her client as in (b), the lawyer does lots of things in her capacity as a representative that do not characterize the client in an immediate or explicit sense, such as listening to him and objecting to the prosecutor. Does it make sense to say of a lawyer who cross-examines a witness - an activity that falls clearly within the domain of actions performed qua representative - that "the lawyer represents the client before the court as cross-examining the witness"? The "as" not only sounds awkward here; more significantly, it collapses the distinct roles of representative and represented, treating the lawyer as a mere substitute for the client.

One could restate the objection by saying that the lawyer represents the client "in" performing certain things: $x$ represents $y$ in doing $z$. Perhaps the characterization is not explicit but implicit in the performance. The idea could be that any act in the capacity of a representative implicitly purports to be in the interest of the represented (here: to the benefit of their defense): in doing $z, x$ represents $y$ as having an interest in doing $z$. Here is a statement that makes this explicit:

(c) In cross-examining the witness, the lawyer represents the client before the court as having an interest in exposing the witness' untrustworthiness.

I think the idea that there is such characterization implicit in acting-for-others is plausible (it will come up again in the final section). But that does not refute the idea that there is a dyadic sense of representative agency. The objection conflates the role or status of a representative with the particular way in which it is exercised. We have switched our focus from the role of the representative in relation to the represented (a) to a specific performance in the course of enacting that role (c). In other words, (c) does not give us a fuller account of (a) that makes explicit a characterization that remains implicit there; it describes yet another relation of representation. We should adjust our analysis accordingly:

(c*) In cross-examining the witness (subject), the lawyer (maker) represents the client (referent) before the court (audience) as having an interest in exposing the witness' untrustworthiness (characterization).

If the idea is that a characterization is implicit in the performance, then the subject of the representation is the particular performance, not the agent. The object would be the client qua having such interest.

The origin of this objection is an ambiguity in statement (a). It might be taken to refer to certain performances on the part of the lawyer (such as her cross-examination), or to her role or status as a representative as such. The objection shows that the idea that representative agency is dyadic needs to be qualified as pertaining to the relation between representative and constituent conceived as roles. These roles by definition involve a two-term relation: a representative (or constituent) is always the representative (or constituent) of someone or something. It is a further claim to say that when that role is executed in some way, those actions may be said to characterize the constituent according to the logic of portrayal. The upshot is that any concrete situation in which representatives act for others will involve a multiplicity of relations of representation, some dyadic and some triadic.

\section{THE REFERENT}

Bearing in mind the difference between dyadic and triadic relations of representation, we can now illuminate the role of the referent. Saward's use of this concept is controversial. Critics dispute that we need this notion in the first place and argue that the idea of something "beyond representation" is at odds with constructivism, as it seems to suggest that what is represented is prior to and independent of representation (Decreus 2013; Disch 2012b; Thompson 2012). Saward's response seems to confirm such a metaphysical reading: "the idea of the referent expresses the sheer materiality of people and things, versus the constructions of meaning that different actors, perspectives and claims may place upon them" (2012, 125-6). By framing the issue this way, Saward casts himself as a moderate constructivist who still affirms some distinction between material reality and constructed representations, as against radical constructivists who question that there is a reality independent of representation. That metaphysical dispute, however, has little to do with the function of the referent in representational claims, properly understood.

We need to consider the referent in connection to both senses of representation. Start with representation-as. As proposed above, in representations-of-something-assomething the referent is related to the object in two ways: by being denoted and characterized. The thing referred to may be a material object (e.g., a drawing of the sun), or it may itself be a representation, as in an interpretation of a painting. The notion of the referent is necessary here not because there is a reality independent of representation, but because without a referent there is nothing that the representational claim purports to be about, which might also be represented differently. The idea of the referent simply expresses this referential purport of our claims. In order to claim that $x$ represents $y$ as $z$, we must be able to mention $y$ in some way other than as $z$. And if competing representational claims did not purport to portray the same thing, then there could be no conflict between them. Whether or not it is warranted, we share this presupposition insofar as we take differing representations to be of the same thing. This is neither to affirm nor deny that some of the things we portray have a material reality independent of the various ways in which we portray them. Literary critics may offer competing interpretations of Sancho Panza's role in Don Quixote, yet Sancho is a discursive construct if there ever was one. Their interpretations can come into conflict only insofar as they are taken to denote the same Sancho and characterize him in inconsistent ways. For something to be a referent of a representational claim is just for it to be 
used (purportedly referred to) in this way. But what it is for that thing to be anything at all is another matter. So the notion of the referent is indifferent as to the metaphysical status of the thing denoted. Where portrayals are concerned, the referent is better understood as a grammatical function of representational claims, than as the metaphysical substratum of representational objects.

What about dyadic relations of representative agency? Here, the analysis in Saward's terms ( $\left.\mathrm{a}^{*}\right)$ seemed to work well enough. We did not encounter the complication that led me to introduce the "characterization" in order to unpack what happened in $\left(b^{*}\right)$. So in dyadic relations of representative agency, object and referent are not related in the same way as in representations-as, where the object denotes and characterizes the referent. The statement that the lawyer is the representative of her client (sec) does not as such allege anything about the client, beyond that she is supposed to act as his representative in the trial. Of course there may be a question as to the identity of the represented. It may be unclear or disputed who the client is. But the statement is not ambiguous in the sense that there remains an element unaccounted for by Saward's framework.

So object and referent do not come apart here as they do in representation-as. Consequently, there is something awkward about Saward's insistence that a representative represents "his idea of his constituency" rather than the constituency itself, just as it would be odd to say that the lawyer is the representative of some idea of her client, and not of the client himself $(2010,36)$. Nonetheless, it seems we need something like an object/ referent distinction here as well. After all, there is an important difference between the client in his capacity as client, and the person as such, considered irrespective of his relation to his legal representative or his role in the trial. And this is part of what Saward's notion of the referent was intended to capture. To approach this from another angle, I said that (a) does not allege anything about the client beyond that he is a client. But it is not trivial that (a) characterizes him as a client, for one thing because it implies, in the context, that he is on trial. It may be tempting to reintroduce a metaphysical notion of the referent here: to say that the referent in representative agency is the real, flesh and blood person. But the legal personality of corporations, let alone the notion of "the people," should caution us against that move. Notice, moreover, that in exactly the same sense there must also be a "referent" of the subject: the person who figures as the representative, in this case the lawyer, is many other things besides a lawyer. Representative and constituency are symmetrical in this respect, which confirms the argument that there is a significant contrast between dyadic and triadic representation. This highlights that both representative and constituency are in some sense constructions, as Saward emphasizes (2010, 47-8).

The way to account for this, I would suggest, is not to import the referent/object distinction but to note again that in relations of representative agency, representative and represented are roles. The distinction we are looking for is between those roles and whoever is performing them. It is true that in statement (a) whoever is the client is denoted and characterized as a client, but not by the representative. The subject of that portrayal is not the representative, but the statement that characterizes the client as a client and the lawyer as his representative. In other words, there are two distinct relations of representation in play-too many for a single "representative claim" to account for. To get a better grip on what is going on, we need a more differentiated account of the representational activities involved.

\section{REPRESENTATIONAL PERFORMANCES}

So far, I have focused on the abstract structure of relations of representation. Let me now flesh out how this bears on the study of political phenomena by shifting attention to the performance of representational claims. We should distinguish carefully between the dyadic relation of representation between representative and constituency, and the triadic relation of portraying-something-as-something - in other words: between representatives and representations. Yet, we should not lose track of Saward's key insight that actingfor-others involves portraying representative and represented in some way. How exactly should we understand portrayal and acting-for-others as political activities?

Consider a typical example of a representative claim, as formulated and analyzed by Saward: "The Liberal Party (maker) offers itself (subject) as standing for the interests of the "family" (object) to the electorate (audience)" $(2010,37)$. The party's claim posits a dyadic relation of representative agency: $x$ ("the Liberal Party") stands for $y$ ("the interests of the "family"). Now, let's shift focus from the content of the claim to the performance of it. This enables us to redescribe what goes on in terms of triadic representation-as: the Liberal Party portrays itself to the electorate as standing for the interests of the "family." (Note that this possibility is signaled by the word "as" in Saward's formulation, but not borne out by his analysis.) Importantly, the terms of our analysis must shift also. The correct way of unpacking this is to say: the Liberal Party (maker), through some statement, picture, or performance (subject), represents itself (referent) as a representative of the interests of the "family" (characterization) to the electorate (audience). The shift of focus entails that we are now analyzing a different relation of representation: not that between the liberal party (subject) and the interests of the "family" (object), but between the party's claim (subject) and the representative relation posited by that claim (object) [viz., the party itself (referent) qua representative of the interests of the "family" (characterization)]. [By the same token, statements (a) and (b) above, considered as claims about relations of representation, are themselves instances of representation-as (in contrast to the relation of representation posited within (a)). That is, (a) portrays the lawyer as the representative of her client, and (b) portrays her as pleading that he is innocent.] 
This shows that making a representative claim (that $x$ acts on behalf of $y$ ) is portraying someone in some way, namely as a representative of some constituency. The subject of such a portrayal is the performance that states the claim. And the object is not the constituency but the relation of representative agency that denotes and characterizes the referents (the purported representative and constituents). As such, the claim does not yet say anything more about the constituency. Another claim would be needed to specify what the interests of the "family" are like, or what is meant by "family" in the first place.

It follows that we should distinguish between representative claims narrowly construed-portrayals of someone as a representative (or constituent) of someone-and representations of someone as being like this-or-that, for example, having such-and-such interests. We could call the former status attributions, in that they attribute a particular role or status to someone, and the latter substantive portrayals, in that they offer some account of their interests, preferences, identity, or the like. To claim that the interests of a constituency are thus and so is not eo ipso to purport to be their representative; to claim a representative role is not eo ipso to represent their interests in a particular way.

Furthermore, neither status attributions nor substantive portrayals are equivalent to representation in the sense of acting-for-others. Of course, operating as a representative often involves portraying one's constituency in one way or another. And sometimes, agents explicitly claim the role of representative in order to perform it. But claiming a role is not the same as enacting that role. What is involved in acting-for-others remains to be explained.

To sum up, there are at least the following types of politically salient representational performance:

- Status attributions: portrayals of someone as having the role of representative of some constituency (or constituent of some representative). The claim itself is a representation-as, but the relation of representation posited by it has a dyadic structure: a representative (or constituent) is by definition the representative (or constituent) of someone or something.

- Substantive portrayals of individuals or groups (or things) as being like this or that - characterizing them in some way (e.g., as having such-and-such interests).

- Representative agency: any action performed in the capacity of a representative (e.g., advocating, legislating, and listening to one's constituents).

- Constituency agency: any action that the represented take as (members of) a constituency-for instance, disputing portrayals of themselves and holding representatives to account.

These are not all mutually exclusive. Arguably, status attributions are a subcategory of substantial portrayals broadly conceived. And of course representatives can perform status attributions and substantive portrayals in their role as representatives.

Distinguishing these forms of activity is both analytically and practically important. For one thing, one may want to criticize what a representative says about her constituency without calling into question that she counts as a representative or is entitled to that role, or vice versa. Imagine the spokesperson of an association of retirees, contributing to a public debate, saying: "I am here to speak for our elderly, who deserve to enjoy their hard-earned pensions, and I say the government should scrap its plan to raise the retirement age." Here are three performances at once, and each is open to challenge. An opponent could challenge the status attribution ("who are you to speak for the elderly"?) or the portrayal ("the elderly already benefited disproportionately"), and counter the representative performance (advocating the contrary policy). Our theoretical vocabulary must be able to distinguish these representational performances and analyze them correctly.

Two examples from the recent debate illustrate how distinguishing these types of representational performance facilitates the study of political phenomena. In a study of what he calls "shape-shifting representation" (2014), Saward argues that political representatives often present themselves differently in different contexts, and distinguishes various strategies and resources that they can use in doing so. This is surely an important direction for research. But Saward's conceptualization still sells it short, because he ties it too narrowly to representation in the sense of acting-for-others. As he defines it, shape-shifting representation is a characteristic activity of representatives. "The shape-shifting representative is a political actor who claims (or is claimed) to represent by shaping (or having shaped) strategically his persona and policy positions for certain constituencies and audiences" $(2014,723)$. Shape-shifting so conceived is clearly a form of representation-as: making substantive portrayals of oneself. But there is no reason to see this as a characteristic activity only of representatives of some constituency. Could not all sorts of political actors portray themselves, their interests, and their preferences in various and changing ways? Think of a strategic voter who professes party loyalty one moment, while choosing differently in the voting booth; a participant in a survey who comes up with a policy position on the spot; or a pundit who peddles different analyses to different media. These shape-shifting representers-makers of portrayals, not necessarily representatives (of a constituency) - are left out of Saward's conceptualization of shape-shifting representation by definition. So conflating two kinds of representational activity, acting-for-others and substantive (self-)portrayal, results in a significant blind spot. Differentiating representational activities as I proposed helps us to see shape-shifting representation as a still more pervasive phenomenon than Saward recognizes. And it opens up a broader range of questions. It would be interesting, for example, to compare the shape-shifting behavior of representatives with that of ordinary citizens (cf. Sheffer et al. 2018).

The ubiquity of representation in politics implied by this argument may raise the worry, recently articulated by Howard Schweber (2016), that the concept loses all specificity. Schweber argues that constructivists like Saward fail to attend to the fact that limits and exclusion are essential to political representation and that they 
overextend the concept of representation to the point where it becomes practically meaningless. Any plausible conception of political representation must affirm certain limits on who can reasonably count as a representative, and any constituency must be defined and bounded in some way. Although Schweber does not distinguish representative agency from representationas, the basic point about limits and exclusion is true for the latter as well: a portrayal of something-assomething excludes other things that the portrayal might have been about (potential referents), and other ways in which the referent might have been portrayed (characterizations). But Schweber's insistence that we need to focus more narrowly on developing a "specifically political conception" of representation to define the (normative) boundaries of representative agency (Schweber 2016, 383-4) overlooks a worthwhile potential contribution of constructivism, which is to draw attention to forms of representational activity-like shape-shifting - which pervade political life even beyond practices of acting-for-others. To appreciate both insights, we need a more differentiated account of the politically significant meanings and activities of representation. We can then acknowledge Schweber's point that any substantive account of representative agency needs an account of its limits, without obscuring the constructivist insight that representation, in the sense of portrayal, is practically ubiquitous in politics (Saward 2010, 79-81). Both forms of representational activity (and perhaps there are others) call for theoretical and empirical attention, but we must first recognize the difference.

\section{DISAMBIGUATING CONSTRUCTIVISM}

Distinguishing analytically between acting for someone and portraying them in some way sheds light on the basic idea of constructivism. Constructivism is typically contrasted with a "standard" view that construes representation in terms of likeness to something given. The quality of representation is then a matter of how accurately it corresponds to the represented; for instance, the degree of congruence between the policy positions of parties and the preferences of their voters. In contrast, for constructivists the interests, identity, and unity of a constituency are not the unproblematic starting point from which representation departs, but are constructed in the process. As Disch puts it: "For Saward and other constructivists [herself included-TF], the standard model $[. .$.$] is fundamentally misconceived$ because it resists acknowledging that representation is a symbolic practice that is constitutive of represented and representative alike." The crux is "to conceptualize representative and represented as linked not by a static 'correspondence' but in a dynamic process of mutual constitution" $(2015,489)$.

I agree that treating constituencies as given rather than politically constructed is problematic, and have no interest in resurrecting the congruence view. But the idea that representation constitutes the represented is highly ambiguous as to the senses of "representation" and of "the represented." The confusion shows up in a misunderstanding, pervasive in the constructivist literature, of an oft-cited remark by Pitkin: "As the 're' in 'representation' seems to suggest [...] the represented must be somehow logically prior; the representative must be responsive to him rather than the other way around" $(1967,140)$. The dismissal of Pitkin on this score is a standard trope among constructivists (e.g., Laclau 2005, 160-1; Saward 2010, 11-9). Even Disch, who offers an otherwise much more sympathetic reading of Pitkin than Saward does, agrees with him that Pitkin errs on precisely this point (2012a, 606; 2011, 108-9). Reconsidering Pitkin's observation in light of the preceding analysis reveals that the priority of the represented, properly understood, is compatible with constructivism after all.

Pitkin's dictum expresses two thoughts: the represented is in some sense "logically prior" to being represented, and a representative ought to be "responsive" to the represented. The former holds both for dyadic and triadic relations of representation, and the latter, which I shall discuss in the next section, is a specification of that idea for representative agency in particular. Recall that in triadic representation-as the object denotes and characterizes the referent. What is denoted (the referent) is logically prior to how it is characterized. So the represented is both prior to the representation, in the sense of the referent, and constructed by it, namely as characterized in the object. Disch appreciates only the second aspect when she says: "the most profound constructivist challenge to the standard account [is] the idea that acts of representation do not refer to the represented in any straightforward way but work to constitute the represented as unified and (typically) as a bearer of interests and demands" (2015, 490). Goodman helps us see that these are false alternatives; representation-as both refers and characterizes.

It is important to see that this account is not mimetic. The referent is not an original to be copied, which can function as a standard of accuracy. That would require that the referent already be characterized as this or that from the start. But the referent of a claim is whatever is picked out in order to be characterized, for some purpose. Of course, the thing in question may well have been characterized before by preceding claims, but it is not now picked out as such. The whole point of a claim to represent-something-as-something is to characterize something anew-whether similarly or differently to preceding representations. An act of portrayal puts prior representations in question, or re-affirms them.

This straightforwardly explains how representationas constructs its object. More radically, could representation-as be said to constitute its referent also? That would mean that the thing denoted comes to be what it is represented as, in virtue of being represented as such. Here, we need to shift our focus from the individual performance to the ongoing practice of portrayal, so as to bring the uptake of the claim into view. This allows representation to feed back into the referent. For example, a self-conscious king might, after seeing a portrait of himself as a majestic figure, gain confidence, adjust his posture, and comport himself 
differently, becoming majestic indeed. What makes this possible is that the person whom the portrayal purports to be about is practically related, as an agent, to the ongoing practice of portrayal. The particular claim to represent something-as-something still purports to denote some referent, and such referent is logically presupposed by the claim. But whatever figures as such may well be ontologically or genealogically dependent on the ongoing practice of portrayal in which that claim is situated, in the sense that it comes to be the way it is by virtue of how that claim is taken up. Arguably, the identity and interests of constituencies are constructed through practices of portrayal in just this way. And we could say the same about the role of representative and constituency. That, I take it, captures much of the thrust of constructivist theories of representation.

But does it capture all of it? We have now made conceptual sense of a modest sense in which the referent (whatever is picked out and characterized in the object) can be presupposed in a claim and yet constituted through the practice of representing-as. Thus, constructivists' rejection of Pitkin's dictum rests on a false dichotomy. The preceding account is modest because it assumed the existence of the thing denoted before the performance of the claim: The portrait had its efficacy only because the not-yet-majestic king saw it and thereby transformed his identity. Could it be that representation-as affords a more radical kind of novelty, where the referent is not just affected by but called into being through representation? Is there room for saying that not just how the referent exists, but that it exists, is called forth by a representational claim?

This question takes us onto the terrain of theories of constituent power. Several authors argue that constitutive representation is key to understanding the founding of political orders and the construction of peoples. The key idea is that a group "needs to be represented as a collectivity in order for it to be a collectivity" (Geenens et al.2015,515; cf. Brito Vieira 2015; Lindahl 2015; Van Roermund 2003). To speak of a people is to portray a multiplicity of individuals as a unity. But this generates a bootstrapping conundrum. Someone must take the initiative to say "we." As Jacques Derrida observes, with reference to the US Declaration of Independence (1986, 10): “The 'we' of the declaration speaks 'in the name of the people.' But this people does not exist. They do not exist as an entity, it does not exist, before this declaration, not as such."

I will not here venture a theory of constituent power, just offer a couple of pointers. First, we should distinguish the substantive portrayal of the people as a whole from the attribution of the status of representative to the persons issuing the declaration, and then we should try to identify the elements of the respective claims. Start with the moment of portrayal. This is clearly an example of representation-as: the declaration portrays a multiplicity as a unity. Derrida's formulation carefully mentions the object of the portrayal ("this people," the people "as such," "as an entity") without conflating it with its elusive referent. But what is the referent here?

I proposed above to interpret the notion of the referent as a grammatical function: for something to be the referent of a claim is just for it to be referred to by the claim. So what, or whom, is the portrayal of the people as a people purportedly about? Tautologically, it is about those people (plural) who are supposed to be the people (singular). It is tempting to interpret this as a reference to an empirically given set of flesh and blood individuals: "the multitude of persons and groups to which the 'we' refers already exists as a physical entity, but this multitude does not exist yet as the political entity known as the American people" (Geenens et al. 2015, 515). But although it certainly does not yet exist as the American people, neither does it exist, exactly, as a physical entity. Rather than a determinate aggregate of existing individuals, I think we should say that "we" refers to the counterfactual multitude of all those who would count as members of the people. This would be problematic on the assumption that one can only refer to things that actually exist, not to imaginary, putative, counterfactual things (cf. Goodman 1968, 21-6). But if the referent is not a metaphysical substratum but a grammatical function of representational claims, there is no reason to assume that. Thus, what figures as the referent may be logically presupposed but chronologically anticipated or prefigured in the claim.

If it seems entirely mysterious how the portrayal of a counterfactual multitude as a unified people could call that people into being, recall what did the trick in the example of the not-yet-majestic king: the uptake of the claim in the ongoing practice of portrayal. Incontrovertibly, someone must perform that uptake, and that someone must exist, if this is to have the efficacy of constituting a new political reality. What is needed then in terms of actual existence is people (plural) responding to the portrayal. But those people come to be part of the referent of the initial claim only retroactively, by taking and treating themselves and each other as denoted and characterized in the claim.

These nuances matter politically because they account for the fact that there are two distinct questions for someone responding to claim to peoplehood. As I mentioned earlier, a portrayal-of-something-as-something is subject to interpretation both as to whom (or what) it denotes, and how it characterizes them (or it). Here, this means that someone could contest the claim to peoplehood by saying "I'm not one of you," or by saying "that's not who we are." The former is to refuse to take oneself as part of the referent of the claim, and the latter is to reject how one is characterized.

Let's turn to the moment of representative agency. The Declaration is written, and signed, "in the name of the people" by its purported representatives. But since the people does not (yet) exist, it could not have authorized the representatives. So the "representatives" are getting ahead of themselves, pretending that what is being done has already taken place. Some authors conclude from this that any attempt to initiate or transform a collective must be "seized" and relies on a "usurpation of sorts" (Lindahl 2015, 168; Brito Vieira $2015,504)$. This alleged necessity of imposition relies on equating the maker of the portrayal of the multitude as a people with a purportedly authoritative representative of the whole people, as in the case of the Declaration. 
That claim to authority is paradoxical, because the representative can at best be retroactively legitimated. I do not dispute that moments of founding typically involve imposition of this sort. But it is not evident that one can generalize this to all we-saying as a matter of conceptual necessity. Here again, we must carefully distinguish representative agency and portrayal. At least in a localized setting, an initiator saying "we" could purport to speak just as a member of the putative collective, inviting others to join in, rather than casting himself as the representative of the whole, thus arrogating the people's voice to himself.

We have now made sense conceptually of the claim that representation constitutes the represented, in a transformative and an initiatory sense, and shown that both depend on the triadic structure of representationas. However, maintaining that practices of portrayal are constructive in these ways tells us little about representation in the sense of acting-for-others. What is involved in portraying someone as a representative of someone, rather than, say, as a fellow citizen, or an illegal alien? What is distinctive about the status or role of a representative (or a constituent) of someone else? That is what theories of political representation usually aim to illuminate, and the challenge remains.

\section{RECOVERING RESPONSIVENESS}

This final section turns to the second idea in Pitkin's dictum - that the representative must be responsive to the represented, and not the other way around. As I mentioned, we can understand this as a specification of the general idea that the represented is in some sense prior. This idea is key to her account of acting-forothers - an account that I think still makes sense, despite the objections from constructivists.

I argued above that the distinction between object and referent is distinctive of triadic portrayals, not representative agency. If that is right, then the distinction between object and referent cannot do the same work here as in the preceding section. "The represented" in this context just refers to the constituency, and although its boundaries may be vague or its identity contested, it is not ambiguous in the way that enabled me to say for representations-as that the "represented" is both prior (qua referent) and constituted by representation (as characterized in the object). That is the upshot of saying that the relation representativeconstituency is dyadic. So it seems that from a constructivist perspective, asserting the priority of the represented here is straightforwardly problematic, because the represented is unambiguously prior. But that is a misleading impression.

All depends on what exactly is meant by "responsiveness," and I cannot presume to settle the interpretative debate on this score (Brito Vieira 2017; Castiglione 2012; Disch 2012a). Let me just sketch a plausible explanation of the priority of the represented in acting-for-others that is perfectly compatible with constructivism. The point here is less to vindicate Pitkin's view than to illustrate the importance of distinguishing representative agency and portrayal for assessing the normative implications of constructivism.

The priority of the represented would clearly be incompatible with constructivism if responsiveness were interpreted as requiring a one-way causal influence, such that representatives' actions are supposed to be determined by the preferences of their constituents and not the other way around. That is admittedly what responsiveness has come to mean in much of the empirical literature (Sabl 2015). And this is exactly how Disch interprets Pitkin's "stricture of unidirectionality," as she calls it (Disch 2011, 109; Disch 2012a, 606).

But Pitkin's idea, I take it, is about the order of justification, rather than the direction of influence. The represented are prior in the sense that their interests are fundamentally at stake in representative agency, not those of the representative. There seems to be no point in having representatives, if they are not supposed to act in your interest. This reveals something about the terms in which the actions of representatives (qua representatives) can be evaluated. Representatives and represented alike can appeal to the interests of the represented in justifying or criticizing the representative's actions. Put differently, the represented are entitled to a justification of the representative's actions in terms of their own interests, while they do not owe the representative justifications in turn. ${ }^{4}$

On this interpretation, being "responsive" toward the represented does not mean that the representative should operate like a one-way conveyor belt, transforming citizens' given preferences into actions or policies. That would presume their interests to be fully transparent to citizens themselves, and short-circuit contestation of how they are to be portrayed. Crucially, the genuine interests of the representedwhatever they might be-are logically distinct from what anyone makes of them. Pitkin certainly does not think that anyone might have unmediated access to those interests. She does say that "we assume that normally a man's wishes and what is good for him will coincide" $(1967,156)$ - but that is a merely prima facie supposition that leaves open the political question of the norm and the exception. For Pitkin, both representatives and constituents are capable of judgment, and when their judgments conflict, neither the representative nor the represented (least of all the theorist) has the last word about how those interests should be portrayed. ${ }^{5}$ Responsiveness, so construed, roughly means

\footnotetext{
${ }^{4}$ Pitkin's formulation is subtly different $(1967,155)$ : “The substance of the activity of representing seems to consist in promoting the interest of the represented, in a context where the latter is conceived as capable of action and judgment, but in such a way that he does not object to what is done in his name." Still, I do not think she means that the absence of objections as such is what determines whether representation is genuinely occurring (Runciman 2007), but the representative's comportment toward actual or potential objections.

${ }^{5}$ See her dissolution of the "mandate-independence controversy." For Pitkin, representatives are neither trustees who must follow their own judgment, nor delegates who must reflect their constituents' views; these are false alternatives precisely because interests require interpretation (1967, 156-67). On refusing anyone the last word, cf. Pitkin $(1966,52)$.
} 
orienting one's actions qua representative toward the interests of the represented according to one's best judgment, while acknowledging that one's judgment is fallible, and comporting oneself toward the represented in a manner that allows for the contestation of those interests.

Thus, someone who claims to put the interests of their constituency first, while operating obliviously to criticism and failing to countenance questions or concerns as to what those interests are, would not genuinely be representing that constituency. The reason is not a lack of correspondence of the purported representative's interpretation of the constituency's interests to the constituents' own interpretation of them or to what those interests "really" are, independently of what anyone makes of them. That would be to make the mistake, discussed in the preceding section, of taking the referent of those substantive portrayals for a criterion or measure of their object. Rather, it is because by insulating oneself from criticism one fails to take any discrepancy between such accounts as an occasion for questioning, and that would miss the point of the activity, which is to act on behalf of the represented, not one's own conceited view of them.

The idea that the actions of a representative purport to be justifiable in terms of the interests of the represented, and not the other way around, in no way implies that the genuine interests of the represented - whatever they might be-are ontologically or genealogically independent of practices of portrayal. Nor does it deny that representatives could have a role in shaping those interests. Understood in this way, the priority of the represented is not a metaphysical commitment to the existence of interests prior to the practices of political representation (in either sense), but a pragmatic commitment concerning the order of justification implicit in the idea of representative agency. One must assume that the represented have interests if the idea of acting for them is to make sense. That is part of the grammar of the concept, so to speak. And if both representative and constituency are capable of judgment, yet fallible, perhaps uncertain, and potentially in disagreement with each other, then it seems appropriate to leave the question of how to characterize those interests contestable.

This is a normative account of representative agency, in the sense that it explains what it means to act as a representative in terms of what a genuine representative does, as opposed to a pretender. If responsiveness in this sense is indeed implicit in the idea of representative acting-for-others, then one cannot call someone a representative without raising such normative expectations. But the notion does not provide a criterion of judgment that would enable us to settle disputes about who appropriately represents whom. Furthermore, the presumption that both representative and constituency are capable of judgment introduces a democratic element, insofar as it attributes an active role to the represented. It does not follow, however, that representation is equated with democracy, since the idea of responsiveness does not, by itself, entail that everyone should be represented equally.
Does this notion of responsiveness do justice to the complexity and dynamism of representation stressed by constructivists, particularly those, like Disch, who reject a principal-agent model and see representation emerging only at the level of a system? Pitkin's refusal to accord anyone the last word sits well with viewing representation as an open-ended and ongoing process. Moreover, the normative standard of "reflexivity" that Disch presents as an alternative to Pitkin's notion of responsiveness is in fact a very similar idea. Reflexivity, she suggests, is a measure of the degree to which a political system renders itself contestable by mobilizing challenges and objections from the represented and taking those into account in structural ways, through a "system of interlocking sites of opinion formation and decision making" (Disch 2011, 113). This strikes me as a promising way to think through what responsiveness might mean on the level of a political system as a whole. But because Disch dismisses the idea of responsiveness and denies categorically the priority of the represented, her account of reflexivity cannot explain why mobilizing contestation rather than instilling acquiescence makes a political system more representative. On my interpretation of responsiveness, this makes perfect sense: It is a way of institutionalizing, at the level of a political system, an orientation toward the interests of the represented and an acknowledgment of fallibility and uncertainty on the part of the representative.

\section{CONCLUSION}

There is not just a semantic difference between two politically salient senses of "representation"-acting-forothers and portraying-something-as-something - but also a logical one: Relations in the former sense have a dyadic structure, while the latter are triadic. Without claiming that these two senses exhaust the meaning of the word, I have exploited this basic idea to sharpen and extend an influential set of conceptual tools for studying political representation, shifting from the singular "representative claim" toward multiple representational activities. I introduced the notion of the "characterization" into that vocabulary, explained the notion of the "referent" in pragmatic rather than metaphysical terms, and distinguished between representative agency and two kinds of portrayal: status attributions portraying someone as a representative or constituent of someone else, and substantive portrayals of someone as thus-and-so. By distinguishing the represented qua referent from the represented as characterized in the object, I explicated how representation could be constitutive, while affirming the logical priority of the represented. Finally, I explicated the normative priority of the represented vis-à-vis representatives in terms of a notion of responsiveness that constructivists can accept.

The resulting conceptual framework yields a differentiated understanding of political representation. Empirically, it enables us to distinguish among various forms of representational performance, and to identify accurately the pertinent elements of representational claims. Conceptually, it breaks open false dichotomies, 
enabling us to recognize the truth in constructivists' view that representation is virtually ubiquitous in politics and in critics' view of representation as a distinctive kind of role, tied to a more narrow range of contexts. Constructivism as such tells us little about the distinctive roles of representatives and constituents (inside or outside of electoral contexts). But it does highlight the significance of practices of portrayal in constituting political agents, collectives, and "the people." Normatively, my analysis shows that constructivists have been overly hasty in dismissing the notion of responsiveness-although what responsiveness means positively and how it might be achieved and assessed are further questions. Further work is required also in democratic theory to examine the significance of various representational activities for understanding constituent power and representative democracy. Perhaps it is true that democratic politics ineluctably involves representation, but we need to specify which forms of representation are vital to democracy and why. Insofar as democracy requires practices of portrayal-representations of "the people" as a unity, as having such-and-such interests or such-and-such a will, and so on - we need to ask which modes of portrayal are conducive to democratic equality and agency. This must not be conflated with the contentious question of whether democracy essentially requires a division of roles between representatives and ordinary citizens.

\section{FUNDING}

The research for this paper was supported by a Venigrant from the Dutch Organization for Scientific Research (NWO).

\section{REFERENCES}

Alcoff, Linda. 1991. "The Problem of Speaking for Others." Cultural Critique, (20): 5-32.

Ankersmit, Frank. 1996. Aesthetic Politics: Political Philosophy Beyond Fact and Value. Stanford: Stanford University Press.

Bourdieu, Pierre. 1991. Language and Symbolic Power. Cambridge: Polity Press.

Brito Vieira, Mónica. 2015. "Founders and Re-Founders: Struggles of Self-Authorized Representation." Constellations 22 (4): 500-13.

Brito Vieira, Mónica. 2017. "Performative Imaginaries: Pitkin versus Hobbes on Political Representation." In Reclaiming Representation, ed. Mónica Brito Vieira. New York: Routledge, 25-49.

Castiglione, Dario. 2012. "Giving Pitkin Her Due: What the 'Representative Claim' Gets Right, and What It Risks Missing." Contemporary Political Theory 11 (1): 118-22.

Celis, Karen, Sarah Childs, Johanna Kantola, and Mona Lena Krook. 2014. "Constituting Women's Interests Through Representative Claims." Politics and Gender 10 (02): 149-74.

Decreus, Thomas. 2013. "Beyond Representation? A Critique of the Concept of the Referent." Representation 49 (1): 33-43.

Derrida, Jacques. 1986. "Declarations of Independence." New Political Science 7 (1): 7-15.

de Wilde, Pieter 2013. "Representative Claims Analysis: Theory Meets Method." Journal of European Public Policy 20 (2): 278-94. Disch, Lisa. 2011. "Toward a Mobilization Conception of Democratic Representation." American Political Science Review 105 (01): $100-4$.
Disch, Lisa. 2012a. "Democratic Representation and the Constituency Paradox." Perspectives on Politics 10 (03): 599-616.

Disch, Lisa. 2012b. "The 'Constructivist Turn' in Political Representation." Contemporary Political Theory 11 (1): 114-18.

Disch, Lisa. 2012c. "The Impurity of Representation and the Vitality of Democracy." Cultural Studies 26 (2-3): 207-22.

Disch, Lisa. 2015. "The 'Constructivist Turn' in Democratic Representation: A Normative Dead-End?" Constellations 22 (4): 487-99.

Disch, Lisa. 2016. "Representation." In The Oxford Handbook of Feminist Theory, eds. Lisa Disch and Mary Hawkesworth. Oxford: Oxford University Press, 781-802.

Fossen, Thomas. 2019. "Language and Legitimacy: Is Pragmatist Political Theory Fallacious?" European Journal of Political Theory 18 (2): 293-305.

Geenens, Raf, Thomas Decreus, Femmy Thewissen, Antoon Braeckman, and Marta Resmini. 2015. "The 'Co-Originality' of Constituent Power and Representation." Constellations 22 (4): 514-22.

Goodman, Nelson. 1968. Languages of Art. Indianapolis: Bobbs-Merrill.

Hall, Stuart. 1997. "The Work of Representation." In Representation: Cultural Representations and Signifying Practices, ed. Stuart Hall. London: Sage, 1-74.

Hobbes, Thomas. 2012. Leviathan. Vol. 2, ed. Noel Malcolm. Oxford: Oxford University Press.

Kröger, Sandra, and Dawid Friedrich. 2013. "Introduction: The Representative Turn in EU Studies." Journal of European Public Policy 20 (2): 155-70.

Kuyper, Jonathan. 2016. "Systemic Representation: Democracy, Deliberation, and Nonelectoral Representatives." American Political Science Review 110 (2): 308-24.

Laclau, Ernesto. 2005. On Populist Reason. London: Verso.

Lefort, Claude. 1988. Democracy and Political Theory. Cambridge: Polity Press.

Lindahl, Hans. 2015. "Possibility, Actuality, Rupture: Constituent Power and the Ontology of Change." Constellations 22 (2): 163-74.

Lord, Christopher, and Johannes Pollak. 2013. "The Pitfalls of Representation as Claims-Making in the European Union." Journal of European Integration 35 (5): 517-30.

Mansbridge, Jane. 2003. "Rethinking Representation." American Political Science Review 97 (4): 515-28.

Montanaro, Laura. 2012. "The Democratic Legitimacy of Self-Appointed Representatives." The Journal of Politics 74 (4): 1094-107.

Mulieri, Alessandro. 2016. "Hasso Hofmann and the Polysemy of Representation." Redescriptions 19 (2): 127-45.

Näsström, Sofia. 2006. "Representative Democracy as Tautology." European Journal of Political Theory 5 (3): 321-42.

Näsström, Sofia. 2015. "Democratic Representation Beyond Election." Constellations 22 (1): 1-12.

Pitkin, Hanna Fenichel. 1966. "Obligation and Consent-II." American Political Science Review 60 (1): 39-52.

Pitkin, Hanna Fenichel. 1967. The Concept of Representation. Berkeley: University of California Press.

Rehfeld, Andrew. 2017. "What Is Representation? On Being and Becoming a Representative." In Reclaiming Representation, ed. Mónica Brito Vieira. New York: Routledge, 50-74.

Runciman, David. 2007. "The Paradox of Political Representation." Journal of Political Philosophy 15 (1): 93-114.

Sabl, Andrew. 2015. "The Two Cultures of Democratic Theory: Responsiveness, Democratic Quality, and the EmpiricalNormative Divide." Perspectives on Politics 13 (2): 345-65.

Saward, Michael. 2010. The Representative Claim. Oxford: Oxford University Press.

Saward, Michael. 2012. "Claims and Constructions." Contemporary Political Theory 11 (1): 123-7.

Saward, Michael. 2014. "Shape-Shifting Representation." American Political Science Review 108 (04): 723-36.

Saward, Michael. 2017. "Performative Representation." In Reclaiming Representation, ed. Mónica Brito Vieira. New York: Routledge, 75-94.

Schweber, Howard. 2016. "The Limits of Political Representation." American Political Science Review 110 (2): 382-96.

Sheffer, Lior, Peter John Loewen, Stuart Soroka, Stefaan Walgrave, and Tamir Sheafer. 2018. "Nonrepresentative Representatives: An Experimental Study of the Decision Making of Elected Politicians." American Political Science Review 112 (2): 302-21.

Sintomer, Yves. 2013. "The Meanings of Political Representation: Uses and Misuses of a Notion." Raisons Politiques 50 (2): 13-34. 
Squires, Judith. 2008. "The Constitutive Representation of Gender: Extra-Parliamentary Re-Presentations of Gender Relations." Representation 44 (2): 187-204.

Thompson, Simon. 2012. "Making Representations." Contemporary Political Theory 11 (1): 111-4.
Urbinati, Nadia. 2006. Representative Democracy: Principles and Genealogy. Chicago: University of Chicago Press.

van Roermund, Bert. 2003. "First-Person Plural Legislature: Political Reflexivity and Representation." Philosophical Explorations 6 (3): 235-50. 